\title{
Commonplace
}

\section{Something's in the Water}

\author{
Baird Howland
}

Published on: Apr 26, 2021

DOI: $10.21428 / 6 \mathrm{ffd} 8432 . f 7 e 7277 \mathrm{~b}$

License: Creative Commons Attribution 4.0 International License (CC-BY 4.0). 
What happens to all the hours that vanish into our TVs, computers, and phones? Everybody knows the story-we turn on a screen and relinquish the reality of the present moment. But in exchange for what? Which media take its place? Over the past few years, I've helped with a research project aimed at answering basically this question, quantitatively, by observing the TV-watching and web-browsing behavior of hundreds of thousands of people in the USA. With special attention paid to news consumption, we've tried to paint a picture of the American media diet.

When this research effort began, in early 2018, I remember there was a terrific desire, on the part of both people I talked to and public figures, to explain why so many people had voted for Donald Trump. This desire was the context of the project and ultimately its motivation, because it kept dragging one particular idea about media into the discourse around the election: the idea that the information supply had somehow become poisoned [1]][2]][]․ For example, "fake news," and "Russian meddling," and "Cambridge Analytica" were all separately blamed for Trump's rise amid a swirling moral panic over how media-especially social media-had warped the

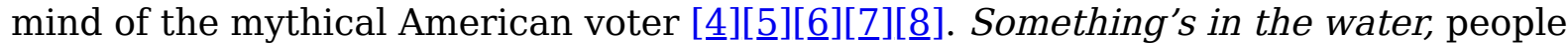
thought.

Since then, Donald Trump-along with the immediate need to explain away his support -has, of course, been dismissed by electoral vote, but the core idea of a poisoned information supply has persisted and grown. The notion that something's in the water now sprouts up all over the place, offering itself as an explanation for other far-right political movements, for public health crises, for distrust of the state and powerful

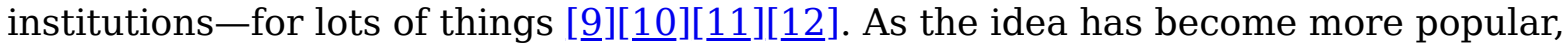
its language has naturally evolved and become more flexible. If just a few years ago the internet was awash with "fake news," today it's drenched with "disinformation" and "misinformation," terms which can refer to a much broader range of things. And those terms are now everywhere, from academic reports to everyday conversation; they appear to us as poisonous vessels which spread through the population like a virus, infecting people with any sort of wrong beliefs. They also entail, subtly, an ideology which sees the individual as being like a modern computer program-an information processor whose input (today's media) begets output (tomorrow's beliefs, behavior).

Truthfully, whenever I hear those words, especially "misinformation", I wince-I feel that someone is trying to sell me something. It is like the phrases "X for social good," 
"artificial intelligence," and "wellness," which-for me, personally-are dead, because they evoke a narrative which is virtually never specified. The experts define misinformation as "false or misleading information" (the distinction between dis- and mis- apparently hinges on the intent of the sender) [13] [14 $][\underline{15}]$. Therefore, given the vagueness of "misleading," they are only a hair more specific than "information"! But "misinformation" is more loaded than "information"-not by a hair, by a mile. The word "misinformation" is like a trojan horse which smuggles into our minds a story of a person who is duped into believing or doing something stupid. In reality, the evidence for misinformation-whatever is exactly meant by it in the context-being the cause of anything significant is often ambiguous at best.

For example, "Black and Hispanic Communities Grapple With Vaccine Misinformation," declares a recent NYT headline [16]. The article, set in a San Jose neighborhood, tells the story of a couple of activists who go door to door, pamphlets in hand, encouraging residents to get vaccinated for COVID-19. The tacit implication from the article's headline and introduction is that misinformation is to blame for the low vaccination rates: "Black and Hispanic communities. . . whose vaccination rates are lagging. . . are confronting vaccine conspiracy theories, rumor and misleading news reports on social media." The problem is the article soon admits that ease of access to vaccine sites probably determines vaccination rates more than anything else; it also details our history of medical violence against Black people. Why then, is it the idea of a conspiracy - of all things-which we are told to imagine as the enemy of Black and Hispanic Communities? This is typical of news and academic reports which both assume and imply, but never establish, the relevance of misinformation.

Our research project represents an attempt to pause, take a step back, return to the initial hypothesis-something's in the water-and explore it, by simply describing the media people consume on TV and online. We focused our analysis especially on news content, because the conventional wisdom (for better or worse) is that news chiefly influences political attitudes. Furthermore, we went out looking, within all the hours of media consumption, for two of the most discussed incarnations of (dis)misinformation, "fake news" and "echo chambers." Both are vague and used in various ways, so part of the work was to define them, and further to show that the qualitative gist of the measurements is not sensitive to some trivial change in the definition. Basically, we took "fake news" to be any content from an expansive list of sites, sourced from previous literature, which tell blatantly false or hyper-partisan stories while posing as legitimate sources. And we took an individual to be in an "echo chamber" (admittedly a bit of a misnomer) if their news diet, on TV or online, is dominated by partisan sources. 
The short version of the results is that TV still matters, a lot. Americans spend overwhelmingly more time watching news on TV than they do watching or reading online [17]. Furthermore, "fake news," the boogey man supposedly haunting the internet, is extremely rare, making up just $1 \%$ of all the time spent on news content, and of course a much smaller fraction of all media. As for echo chambers, they are around three times more prevalent on TV than online, despite their being popularized as a phenomenon of the internet. You can look at the results in more detail, below.

The picture that has emerged from the project, which is ongoing, contradicts the conventional wisdom of Americans drowning in fringe, polarizing online news. It also suggests that TV still has more influence than the internet over political beliefs. But having said that, the results are necessarily humble: they are descriptive, not causal; they do not explain why Trump won; and they definitely do not contain a prescription for how to "save democracy." If there is a bigger lesson beyond the narrow facts of the report below, it's only something that should be extremely obvious: whatever plagues our culture and how it constructs its social epistemology cannot be understood by obsessing over a single social media platform or a single category of misinformation. More broadly-and more crucially-if we insist on viewing people as information processing machines, then at least construe their "input" as not just today's media, but all of the lived experience and all the culture and history through which beliefs and behavior are constructed. In such a bigger effort to dissect and perhaps improve the culture, we hope this research might be in a small way helpful.

\section{Results}

We relied on The Nielsen Company's large and nationally representative desktop web and TV panels, along with mobile browsing data from a different source, to create a picture of the American media diet. Below are the main takeaways from a couple analyses.

Evaluating the Fake News Problem at the Scale of the Information Ecosystem $\underline{\text { Science Advances }}$

By "fake news," we mean a set of several hundred websites which the existing literature has identified as being blatantly false (e.g., small sites you've likely never heard of that utterly fabricate news stories) or hyper-partisan (e.g., Breitbart.com), 
while posing as legitimate sources. By "news," we mean a set of several thousand news websites compiled in previous academic literature and all of the TV programs labeled as news by Nielsen. Our analysis includes a method to impute the amount of news and fake news viewed on social media. See the article's supplementary materials for more details.

\section{Time Frame: 2016-2018}

1. Americans consume 5 times more news on TV than online (54 minutes/person/day, and 10 minutes / person / day [m/p/d], respectively).

a. 18-24-year-olds, the age group with the highest fraction of news as online news, still consume nearly twice as much news on TV than online (9 to $5 \mathrm{~m} / \mathrm{p} / \mathrm{d}$ ).

b. 55+-year-olds, the age group which consume most online news on average (13 $\mathrm{m} / \mathrm{p} / \mathrm{d})$, spend a whopping $94 \mathrm{~m} / \mathrm{p} / \mathrm{d}$ with TV news.

2. "Fake News" comprises only $0.15 \%$ of the American media diet, and $1 \%$ of the news viewed. Most people are essentially never exposed to fake news.

3. News consumption of any sort comprises at most $14 \%$ of all TV and internet browsing.

A graphic of kinds of news Americans consume, broken down by age group: 


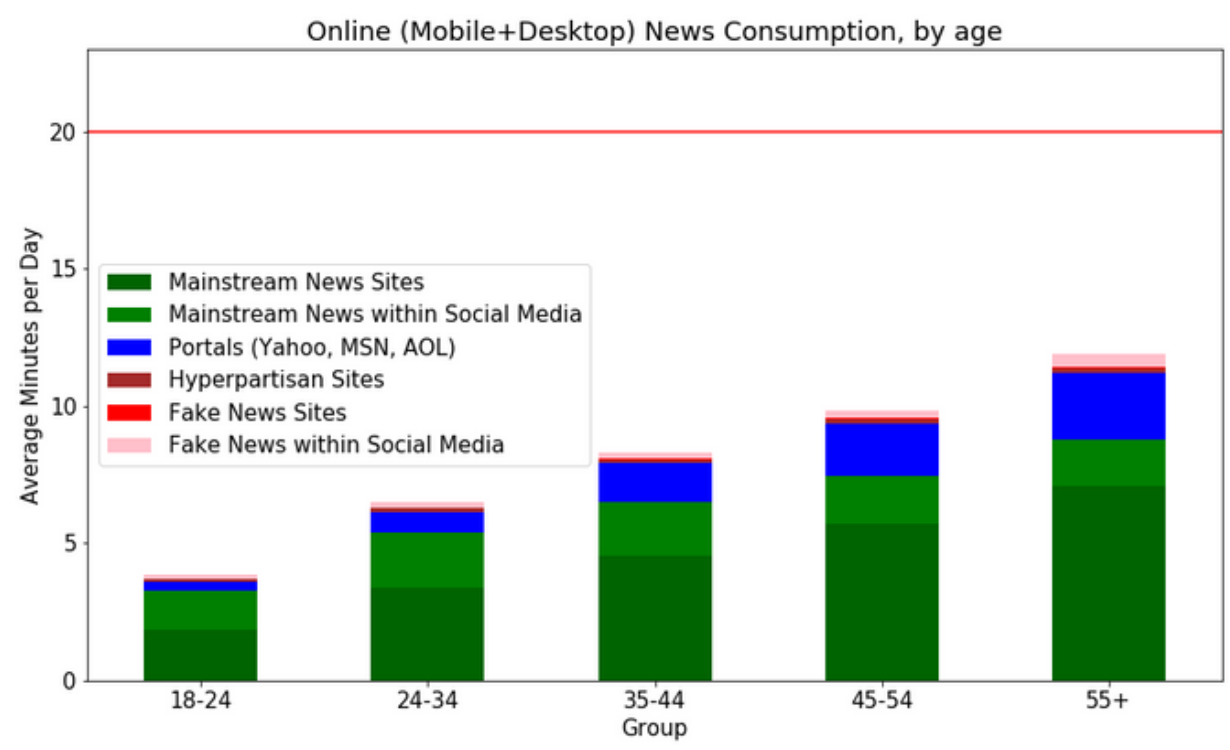

Breakdown, by age group, of news consumption online.

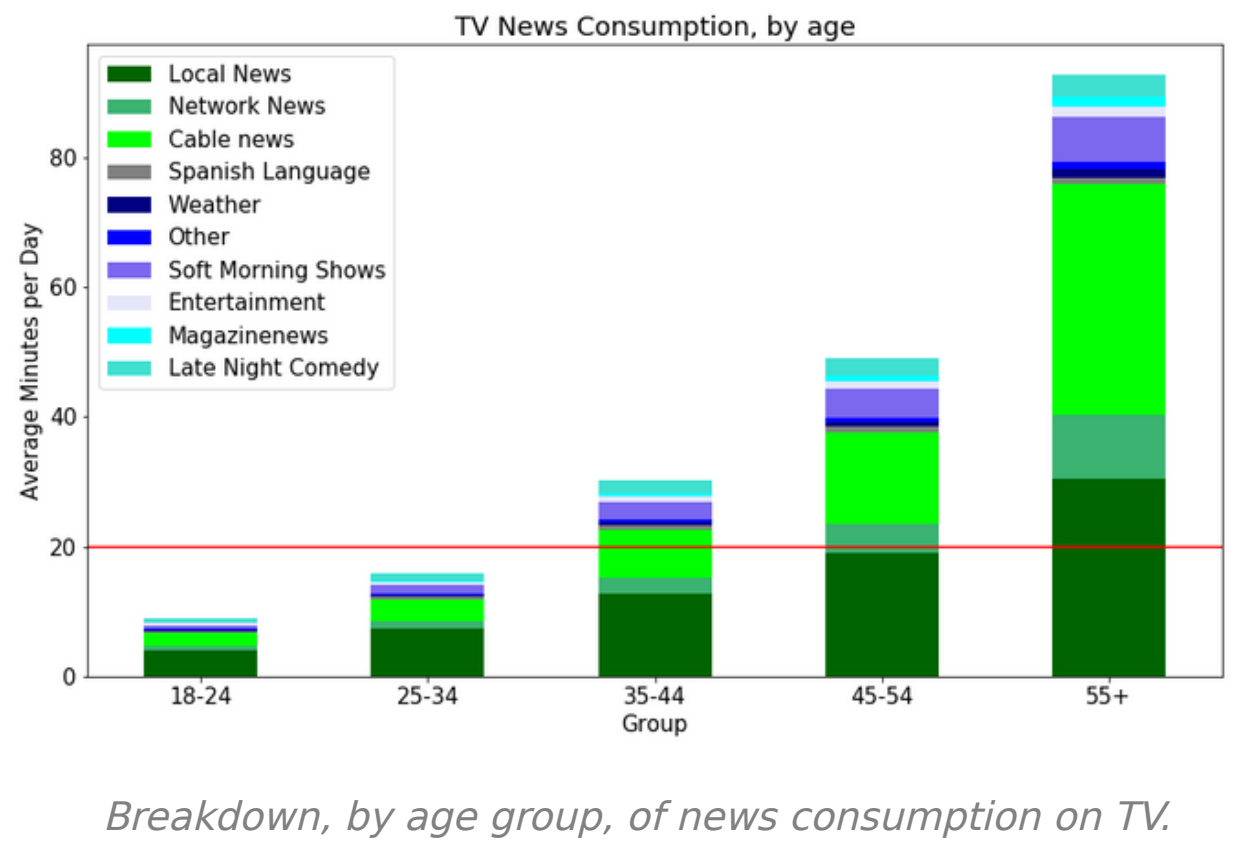

Echo Chambers Thrive Offline: a Cross-Platform Analysis of News Consumption

This work is ongoing, and publication hopefully forthcoming. By "echo chamber," we mean a news diet which is dominated by far right or far left news sources. This definition does not include social media posts per se but does implicitly capture news 
articles and videos which are shared on social media. The analysis of echo chamber sizes includes checks to ensure the qualitative results listed below are insensitive to reasonable changes in the operationalization of "dominated," "far right, " and "far left."

\section{Time Frame: 2016-2019}

1. TV echo chambers are bigger. Echo chambers of TV news (both right- and leftleaning) are 3-4 times more prevalent than the echo chambers online, with about 15\% of Americans being in a right-wing TV echo chamber.

2. TV echo chambers are stickier. We analyzed behavior on a monthly basis and consider "being in an echo chamber" as having a news diet dominated by partisan sources over the course of a full month. We found that upon joining an echo chamber, those in TV echo chambers are much more likely than those in web echo chambers to stay there (i.e., to continue having their news diet dominated by partisan sources). For example, $28 \%$ of people who join a right-wing TV echo chamber have not left six months later, compared to just $6 \%$ of those who joined a right-wing web echo chamber.

3. Echo chambers online are shrinking; the total number of people that get any amount of news on TV is shrinking; echo chambers on TV are growing, and their increase is driven by people changing their viewing allegiances from moderate network news to the Fox News or MSNBC.

Baird is a Ph.D. student at the Annenberg School of Communication at UPenn and can be contacted at baird.howland@asc.upenn.edu.

\section{Citations}

1. Tufekci, Zeynep. "How Social Media Took Us from Tahrir Square to Donald Trump.” MIT Technology Review, MIT Technology Review, 2 Apr. 2020, www.technologyreview.com/2018/08/14/240325/how-social-media-took-us-from-tahrirsquare-to-donald-trump $/$.

2. Bosworth, Andrew. On Facebook's Role in Electing Donald Trump. Facebook, 7 Jan. 2020, 1:51 p.m., https://www.facebook.com/boz/posts/10111288357877121 3. Madrigal, Alexis. "What Facebook Did to American Democracy." The Atlantic, 16 Nov. 2017, www.theatlantic.com/technology/archive/2017/10/what-facebook- 
$\underline{\operatorname{did} / 542502}$.

4. Blake, Aaron. "A New Study Suggests Fake News Might Have Won Donald Trump the 2016 Election." Washington Post, 3 Apr. 2018, www.washingtonpost.com/news/the-fix/wp/2018/04/03/a-new-study-suggests-fakenews-might-have-won-donald-trump-the-2016-election.

5. Kurtzleben, Danielle. “Did Fake News On Facebook Help Elect Trump? Here's What We Know." NPR, NPR, 11 Apr. 2018, www.npr.org/2018/04/11/601323233/6facts-we-know-about-fake-news-in-the-2016-election. $\doteq$

6. Parkinson, Hannah Jane. "Click and Elect: How Fake News Helped Donald Trump Win a Real Election." The Guardian, 20 Aug. 2018, www.theguardian.com/commentisfree/2016/nov/14/fake-news-donald-trump-electionalt-right-social-media-tech-companies.

7. Graham-Harrison, Emma, and Carole Cadwalladr. "Revealed: 50 Million Facebook Profiles Harvested for Cambridge Analytica in Major Data Breach.” The Guardian, 3 Feb. 2020, www.theguardian.com/news/2018/mar/17/cambridge-analytica-facebookinfluence-us-election. $\subseteq$

8. Mayer, Jane. "How Russia Helped Swing the Election for Trump." The New Yorker, 9 July 2019, www.newyorker.com/magazine/2018/10/01/how-russia-helped-toswing-the-election-for-trump. $\doteq$

9. The Policy Institute at King's College London and Ipsos MORI. Brexit misperceptions. October 2020. https://www.kcl.ac.uk/policy-institute/assets/brexitmisperceptions.pdf $\underline{\text { df }} \leftrightharpoons$

10. Dunt, Ian. "New Study Shows Brexit Is Drenched in Fake News." Politics.Co.Uk, 29 Oct. 2018, www.politics.co.uk/blogs/2018/10/29/new-study-shows-brexit-isdrenched-in-fake-news. $\triangleq$

11. Spring, By Marianna. "Coronavirus: The Human Cost of Virus Misinformation." $B B C$ News, 27 May 2020, www.bbc.com/news/stories-52731624.

12. Ognyanova, K., Lazer, D., Robertson, R. E., \& Wilson, C. (2020). Misinformation in action: Fake news exposure is linked to lower trust in media, higher trust in government when your side is in power. Harvard Kennedy School (HKS) Misinformation Review. https://doi.org/10.37016/mr-2020-024 
13. Rinehart, Aimee. "Fake News. It's Complicated.” First Draft, 29 Mar. 2021, firstdraftnews.org/latest/fake-news-complicated..

14. "Misinformation." The Merriam-Webster.Com Dictionary, www.merriamwebster.com/dictionary/misinformation. Accessed 13 Apr. $2021 \boxminus$

15. “Disinformation." The Merriam-Webster.Com Dictionary, www.merriamwebster.com/dictionary/disinformation. Accessed 13 Apr. 2021.

16. Frenkel, Sheera. "Black and Hispanic Communities Grapple With Vaccine Misinformation." The New York Times, 11 Mar. 2021, www.nytimes.com/2021/03/10/technology/vaccine-misinformation.html..

17. Allen, Jennifer \& Howland, Baird \& Mobius, Marine \& Rothschild, David \& Watts, Duncan. (2020). Evaluating the fake news problem at the scale of the information ecosystem. Science Advances. 6. eaay3539. 10.1126/sciadv.aay $\underline{3539}$. 